\title{
sciendo
}

CIVIL AND ENVIRONMENTAL ENGINEERING REPORTS

E-ISSN 2450-8594

CEER 2021; 31 (3): 0037-0053

DOI: 10.2478/ceer-2021-0033

Original Research Article

\section{COMPARISON OF LEAK DETECTION METHODS USED FOR TESTING LARGE AREA MEMBRANE ROOFS FOR DURABILITY ASSESSMENT PURPOSES}

\author{
Barbara KSIT ${ }^{1}$, Maria RATAJCZAK ${ }^{1 *}$, Agata ŻYLIŃSKA ${ }^{1}$ \\ Poznań University of Technology, Faculty of Civil and Transport Engineering
}

\begin{abstract}
This article presents different types of commercially available roof waterproofing membrane systems used on roofs with large surface area. It deals with the causes of deterioration of such membranes due to environmental factors and describes the tests used to detect leaks and determination of the severity of deterioration of polymeric membranes taking into account the properties declared by their manufactures. The last part of the article is a case study comparing a brand new membrane with a membrane after 27 years in service.
\end{abstract}

Keywords: roof with large surface area, membrane, waterproofing systems, durability, leak

\section{INTRODUCTION}

Roofing membranes are an option of choice for covering roofs with large surface area. Low areal weight (mass per unit area), easy and fast installation and durability are their main advantages over their counterparts. Membrane roofing systems feature a low areal weight, a most desired characteristic in the case of large roofs.

\footnotetext{
* Corresponding author: Poznań University of Technology, Faculty of Civil and Transport Engineering address, maria.ratajczak@put.poznan.pl, +48 616652168
} 
Such roofs are exposed to various environmental factors affecting their durability. In analysing the degree of deterioration of a roofing membrane consideration should be given to the surroundings, building orientation, height and location, parameters of adjacent buildings or structures and presence of roof parapets. There are several non-destructive techniques for testing membrane roofing systems for damage.

EN 13956 [7] classifies waterproof roofing membranes in the group of elastic waterproofing products. This standard gives the definitions and specifies the properties of the respective products, sets out the requirements, describes the test methods and defines the principles for assessing the compliance with the standard requirements.

\section{TYPES OF ROOFING MEMBRANES}

Roofing membranes may play the role of either an airtight ("housewrap") or waterproofing layer [12]. The nomenclature used in relation to different types of roofing membranes can be misleading to people lacking adequate knowledge. Highly and low permeable membranes used as underlay or roof covering material play different roles in a roof system, and therefore they have considerably different parameters, including vapour permeability (resistance), areal weight or UV resistance. Roofing membranes feature a high vapour permeability (or low resistance), about ten times greater areal weight than high resistance underlays and a high resistance to long-term UV exposure.

In the classification system applied in the standard, underlays are classified in the group flexible sheets for waterproofing and roofing membranes in the group of plastic and rubber products.

The group of flexible sheets for waterproofing includes low and high resistance underlays, which according to EN 13859 [6], are further divided as follows:

- high resistance underlays: vapour barriers and vapour retarders.

- low resistance underlays (diffusion-equivalent air layer thickness of less than $0.3 \mathrm{~m}$ ): light-weight membranes and highly-breathable screens.

In general terms, membranes can be classified as homogeneous or heterogeneous depending on their make up. Homogeneous membranes are built of one ply only. Heterogeneous membranes, in turn, in most cases are made up of three plies: surface layer responsible for waterproofing properties, reinforcement of polyester or glass fibre mesh or mat and a backing layer, for example laminated polymer or glass fibre mat. An example of two ply materials are non-reinforced high resistance underlays.

PVC and FPO membranes are the most popular roofing materials specified for roofs with large surface area. Polymeric waterproofing membranes can be 
grouped according to the type and quality of the plastic used in their production, i.e.:

- PVC-P based membranes - a standard plasticised PVC system or a highquality PVC based material,

- polyolefin elastomer based membranes, based on high-quality elastic polyolefins FPO-PP, or top-quality FPO-PP plastic, a blend of special PP polymers,

- EPDM (ethylene-propylene-diene terpolymers) based membranes, also called rubber membranes.

Among thermoplastic polymers PVC is the most popular material of choice for production of sheet waterproofing materials. FPO based synthetic membranes, which have been on the market for about 30 years, are a kind of successor of PVC membranes on the path of technological advancement. Although a bit more difficult in application, they offer a state-of-the-art alternative to widely known and used PVC membranes.

\section{DURABILITY AND CAUSES OF DETERIORATION OF ROOFING MEMBRANES}

Roof covering is the uppermost layer of the roofing system, whose role is to protect from environmental factors the separating and load-carrying components of the roofing system. The roof waterproofing system is directly exposed to weather conditions. As a result, the material gradually deteriorates over time, losing to some extent its protective properties, which has an effect on the durability of the protected structure as a whole $[16,15]$.

The environmental factors which have a bearing on the durability of roof membranes include wind, rain, snow, sunlight, water vapour, hail, air pollution, biological factors and the associated phenomena, including ponding water, buildup of foreign matter/ dirt, and growth of vegetation and fungi on the surface of the membrane roofing system.

The loads acting on a roof covering can be divided into mechanical and thermal loads of high or moderate severity. An example of mechanical loads is negative wind pressure (suction), a high impact load to which much attention is paid in the design of the roof covering system [10]. Negative wind pressure is the cause of damage to roof coverings during strong storms or hurricanes (Fig. 1) [22, 13].

Snow load must also be taken into account in the design. An important issue in the operation phase is to remove snow carefully to avoid damage to the roof covering. Snow staying on the roof for longer periods of time, as well as ponding water can cause overloading and lead to roof leaks $[19,21]$. The process of deterioration is aggravated by any movements and deflections of the supporting structure. In addition, in roofing systems supported by light-weight structures, the 
waterproofing layer is exposed to dynamic actions caused by the vibration of the structure. Furthermore, one should not forget about imposed loads during roofing works. While the design assumes only a minimum level of traffic load on the roof, some visits may be necessary, for example in relation to the required roof maintenance. Soft thermal insulation can also make the roof covering more prone to damage. Besides a higher risk of mechanical damage to the waterproofing layer, dimensional changes of soft insulation material resulting from temperature variations may induce additional stresses in the roof covering.

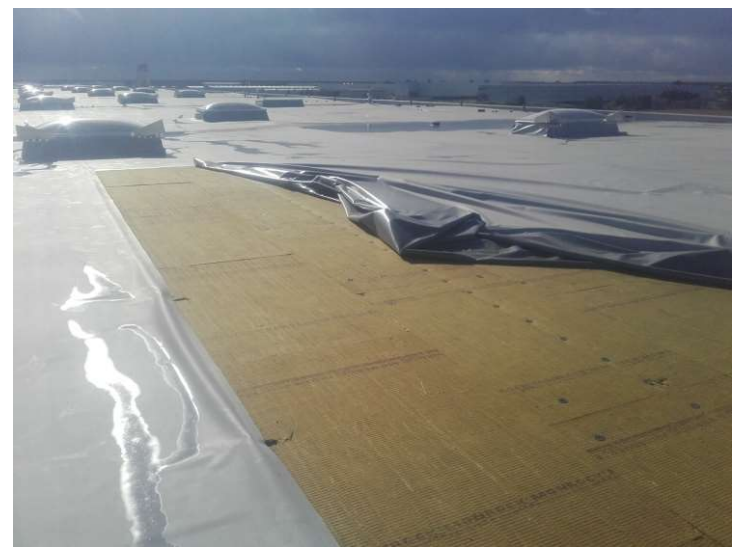

Fig. 1. Damage to roof sheathing caused by the action of wind [13]

Thermal loads include temperature variations (exceeding the operating temperature limits, for example $-30^{\circ} \mathrm{C}$ and $+80^{\circ} \mathrm{C}$ ), accumulation of heat and sudden temperature drops caused by weather phenomena, such as thunderstorms in summer.

The occurrence and severity of the external impacts depend on the location, height and orientation of the building and its surrounding features.

The durability of waterproofing membranes for roofs is defined by their tensile strength. The main environmental factor affecting their durability is sunlight. Stabilising agents are added during production of roof membranes to counteract the determinable effect of this exposure. However, their addition rate and effectiveness are limited. Roof coverings exposed to high levels of sunlight are highly susceptible to deterioration. This exposure can, over time, lead to development of cracks and even complete destruction of the waterproofing layer. Therefore, in assessing the effect of environmental factors on the roof covering durability one should consider the location, height, orientation of the building and its surrounding features.

Nearby trees or taller buildings shading the roof surface will always be beneficial to the roofing membrane durability. However, there is an opposite aspect of this 
matter. Forests increase the humidity of air, promoting the growth of vegetation on the roof surface and there is an increased risk of mechanical damage by branches torn off by a wind.

Also proximity of tall buildings will not always be beneficial to the roof covering, such as, for example, in highly urbanized or industrial areas. In these locations heat generated by exhaust emissions and other pollution may be trapped in the depression, and this will offset the benefit of protection from detrimental effects of solar radiation. Factories and other manufacturing sites located nearby will, in addition, increase the chemical load. Build-up of dirt on the roof surface will entail more frequent roof maintenance and can also lead to undesired chemical reactions due to material incompatibility which may finally damage the membrane.

The wind load is influenced by tall features located around flat roofs [10]. Due to such features, wind cannot accelerate to such speeds as it does in open terrain where the force of wind can increase greatly due to a lack of obstacles on the way. Negative wind pressure can completely destroy the roof covering.

The pullout resistance of fasteners is specified based on the wind load value. In the case of high negative wind pressure conditions a mixed fixing system is recommended, in which the roof covering is bonded with adhesive and the waterproofing and thermal insulation layers are mechanically fixed to the roof framing. It is worth noting that the action of wind is not the same all over the roof. In this respect four roof zones are distinguished: corners, perimeter, exterior fieldof-roof, and interior field-of-roof. A parapet wall may be provided at the roof edge to reduce the wind uplift force. Depending on its height, a percentage reduction in terms of a reduction factors is applied, e.g. for a $10 \mathrm{~m}$ high building a 1 meter parapet wall will reduce negative pressure acting on the corner zones by $28 \%$. Therefore, in open terrain, buildings should be provided with parapet walls to minimize the adverse effects of wind on the roof covering.

Waterproofing membranes feature high permeability to water vapour. Due to the lack of ventilation of the roof, this feature is intended to ensure efficient evacuation of entrapped water vapour. The layers of the roofing system are laid one on top of the other without any ventilation gap in between. This being so, factors such as temperature changes can cause condensation of water vapour under the roof covering and the resulting moisture will affect mainly the remaining layers and the roof framing system. However, this is a rare cause of moisture problems. The most common problem is dampness and leaks at joints between membrane sections and between the membrane and roof details. The main property of roof membranes is the waterproofing performance and thus any leaks, other than caused by perforation should be attributed to long-term deterioration of the membrane. In any case, water vapour should not be pointed to as the cause of the moisture problem. That said, water vapour generally plays a major role in development of roof damage. 


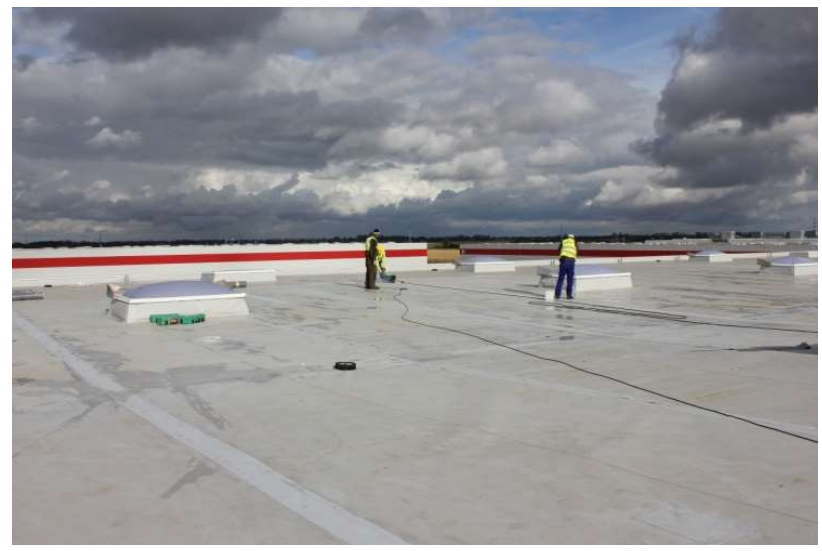

Fig. 2. Ponding water due to incorrect roof falls [Photo by Barbara Ksit]

Other sources of high humidity of surrounding air include lakes and other inland water bodies and marine waters. In the seaside areas the roof covering can be additionally affected by wind borne sand, which, after being deposited on the roof surface, creates an ideal substrate for the growth of lichens, in particular in shaded places. In mountainous areas, in turn, the waterproofing layer will have to cope with very low temperatures and high winds.

Roof orientation has a significant bearing on the ageing of roof membranes due to UV radiation and heat. These effects will be more severe on the south facing slope as compared to the north facing slope of the roof. In the case of high-quality membranes it will take much longer before this difference has become evident.

The durability and long-term stability of polymer-modified membranes is specified by their manufactures in special reports containing a wide range of longterm performance data. On this basis, the service life of PVC membranes is estimated at a minimum of 25 years (irrespective of the climate zone) [3], and over 50 years for FPO membranes [17].

The following graphs show the results of durability tests carried out on samples of PVC membranes taken from 15-27 year old roof coverings. The input data were obtained from a long-term durability report of PVC membranes [3]. These data include tensile strength and ultimate elongation of membranes reinforced with Stype polyester (Fig. 3, Fig. 4) and glass fibre mat (Fig. 5, Fig. 6). The analysed samples were obtained from several buildings located in North America (25 No.) and Europe (20 No.). Taking account of different locations, the procedures from 
COMPARISON OF LEAK DETECTION METHODS USED FOR TESTING LARGE AREA 43 MEMBRANE ROOFS FOR DURABILITY ASSESSMENT PURPOSES

ASTM D4434 [2] were applied for the material from North America, while the samples obtained in Europe were tested according to DIN 16726 [4] and SIA V $280[18]$.

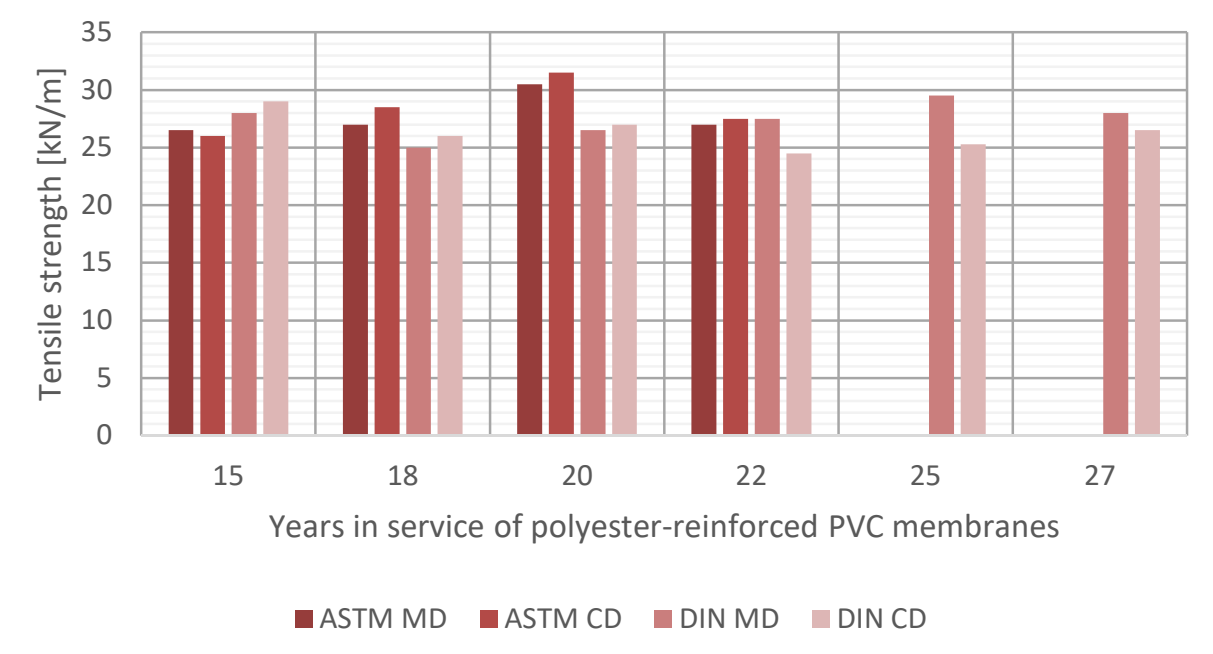

Fig. 3. Tensile strength of PVC membranes reinforced with S-type polyester (MD machine direction, $\mathrm{CD}$ - cross-machine direction) [3]

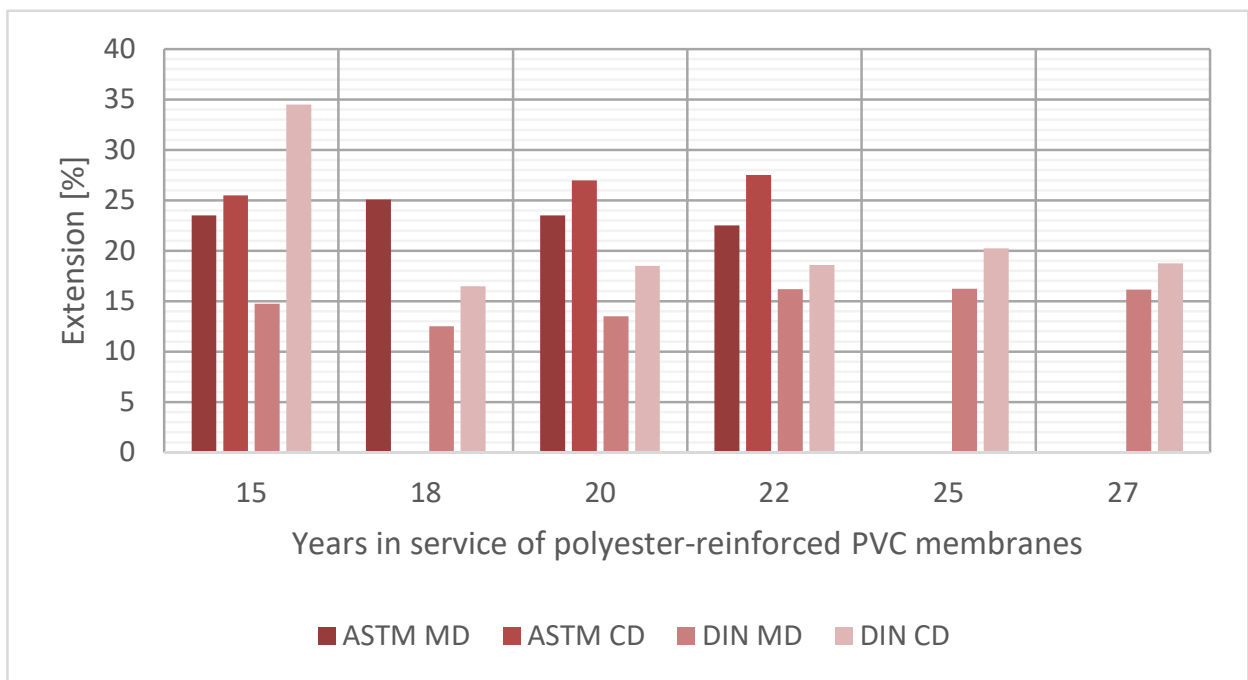

Fig. 4. Ultimate elongation of PVC membranes reinforced with S-type polyester (MD machine direction, $\mathrm{CD}$ - cross-machine direction) [3] 
According to ASTM D4434 [2], the minimum required tensile strength is $35 \mathrm{kN} / \mathrm{m}$ and according to DIN 16726 [4] it is $16 \mathrm{kN} / \mathrm{m}$. According to the DIN requirements, all the tested samples, both North American and European ones, met the requirements for brand new products, exceeding the minimum threshold by 60 $75 \%$. On the other hand, North American samples obtained $70-90 \%$ of this value, yet with the application of the $35 \mathrm{kN} / \mathrm{m}$ requirement. Changes in ultimate elongation due to long-term exposure in service are shown in Figure 4. The tested North American samples reached the minimum ultimate elongation of $15 \%$ as required by ASTM D4434 [2], and all samples reached the minimum value of 10 $\%$ as per DIN 16726 [4].

The values of tensile strength and ultimate elongation were compared also for PVC membranes reinforced with glass fibre mat (G-type) (Fig. 5, Fig. 6). During the tests carried out according to ASTM D4434 (North American samples) [2] and SIA V 280 (European samples) [18] it was observed that, strangely enough, the tensile strength tended to increase between 15 and ca. 22 years in service. In the case of these products it is important to note that the strength parameters are defined primarily by the properties of the polymer component. Therefore, in strength tests the thickness of the specimen is recorded and the strength value is given in MPa. As the plasticizer content decreases over time, the polymer loses its flexibility, which can lead to a higher tensile strength. The data obtained on membranes after 20 years in service do not provide sufficient basis to predict further progress of the described changes. All the tested samples satisfied the minimum tensile strength requirements of the American and Swiss standards.

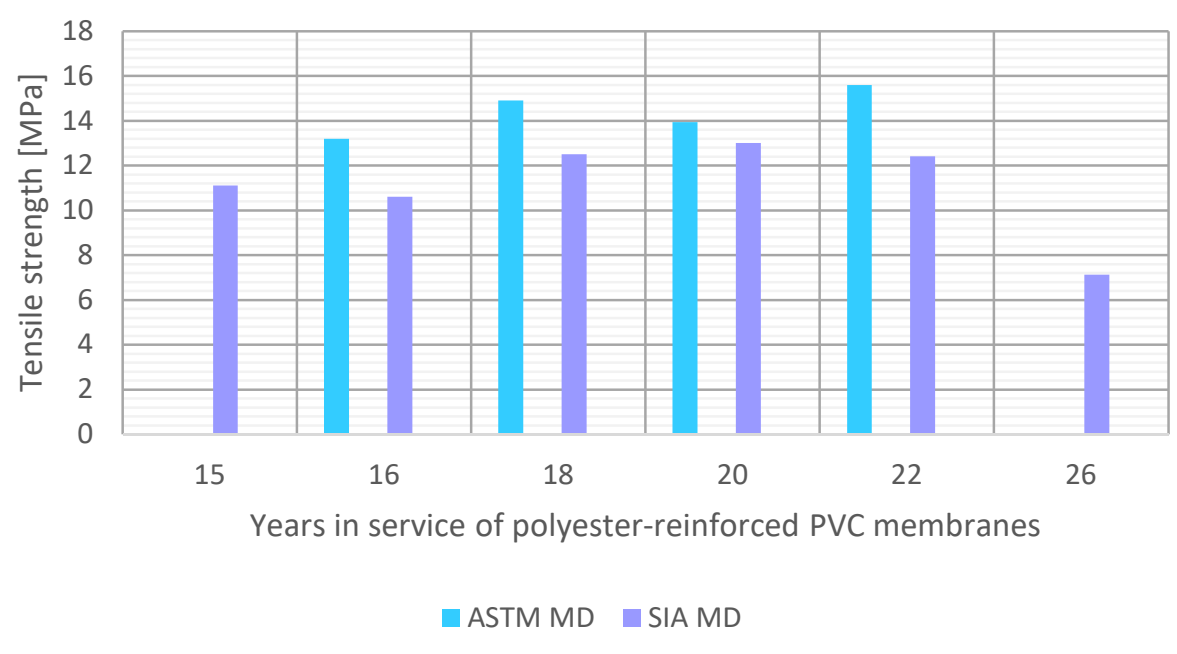

Fig. 5. Tensile strength of glass mat reinforced PVC membranes [G-type] (MD machine direction) [3] 
For brand new materials the minimum required elongation at break is $250 \%$ according to ASTM D4434 [2] and 150\% according to SIA V 280 [18]. The tested samples, after $15-26$ years in service, on average achieved about $61 \%$ and $84 \%$ of the values required by the US and Swiss standards respectively. It was determined that this deficiency has no significant effect on the further operation the roof coverings in question. The membrane was judged to still serve its purpose [3].

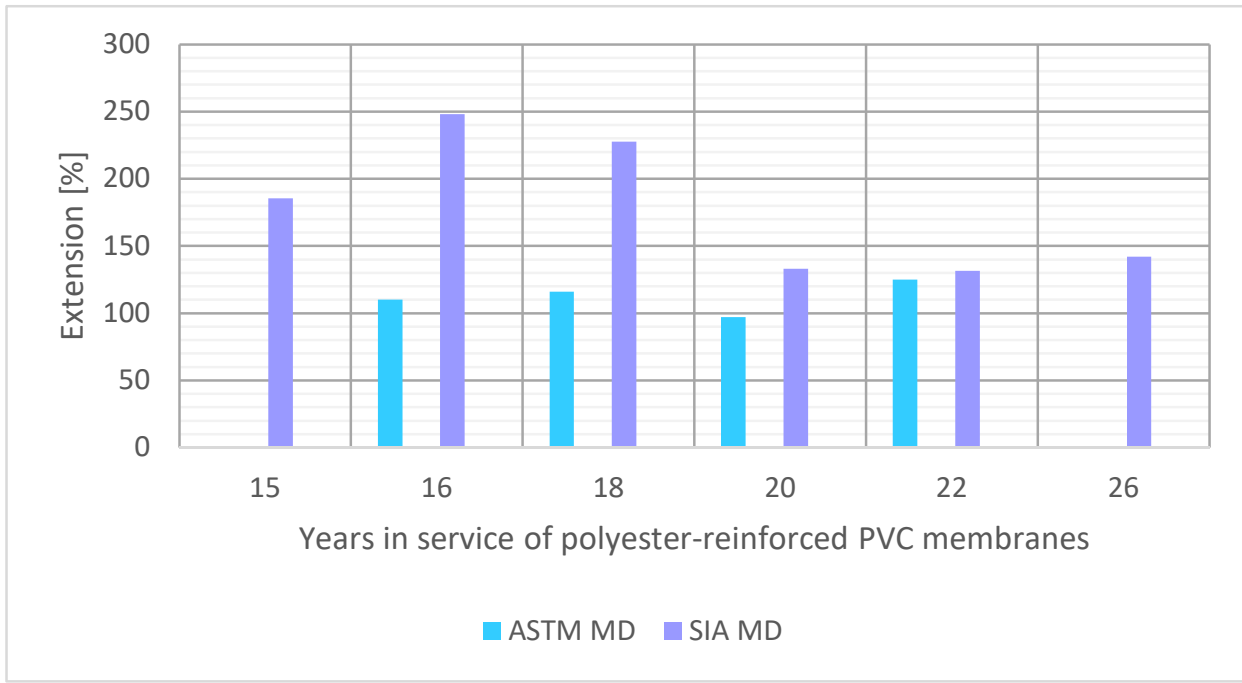

Fig. 6. Ultimate elongation of glass mat reinforced PVC membranes [G-type] (MD machine direction) [3]

\section{TESTS OF MEMBRANE ROOF COVERINGS}

The durability of waterproofing membranes applied on flat roofs depends to a large extent on their water tightness. Several techniques are used to detect leaks of membrane roof covering during service. Some of them cause damage to the roofing system layers during the test (destructive techniques), other leave them intact (non-destructive techniques). The latter use water, gas (or smoke), nuclear backscattering, infrared imaging (thermography), electricity, and vacuum technologies to detect water leaks [20].

\subsection{Water ponding test}

This is the most popular and best known test method used for testing the integrity of flat roof coverings, according to the procedure described in [1]. It is used predominantly on new built roofs. The test is done before handover of the building. After prior sealing, water is poured on the roof until a pond a few to over 
a dozen $\mathrm{cm}$ deep has developed. This method will not, however, determine the exact location of leakage, detect small discontinuities or allow easy determination of the amount of the water penetrating through. Thus the conformity of the completed roof work can be assessed only qualitatively and not quantitatively. Besides, this method can be used only if the resulting additional load can be safely imposed on the structure. Parapet walls around the roof perimeter are an additional requirement. On green roofs and roofs covered with pavement flags or gravel use of this method would be problematic. The imposed loads make this method completely unsuitable for large roofs. A number of other non-destructive methods can be used as an alternative to the above-described water ponding method, somewhat obsolete and limited in application. These include gas detection methods which are described below.

\subsection{Gas detection methods}

Gas detection methods [1] use different gasses, namely smoke, hydrogen and helium and are called accordingly. In this method a penetrating gas is injected under the waterproofing layer. Leaks are detected by means of gas detectors or visually. A low density gas should be used to penetrate easily, which, in addition, must not be harmful to human health or to the environment. During the test, small holes are made in the waterproofing layer through which the penetrating gas is introduced. For periodic testing flexible tubes can be mounted under the waterproof membrane, thus avoiding perforation for the purpose of testing. This method can be successfully used, for example for testing the integrity of membrane seams. It is not suitable for roof coverings that are permanently bonded to base. It can be used for inverted roofs, provided that the existing thermal insulation may be temporarily removed to introduce the measuring probe and enable distribution of the penetrating gas throughout the roof space. Accuracy of measurement is a clear advantage of gas methods. In addition, the leaks can be quickly located.

\subsection{Smoke test}

Smoke test [1] is one of the popular and simple gas detection methods in which smoke that is completely harmless to human health is used (composed of $95 \%$ nitrogen and 5\% hydrogen). During the test water mist will become visible, allowing visual detection of leaks. Colour can be added to facilitate such detection. The advantage of the smoke method is its wide range of application. It can be used for detecting defects on all types of roof coverings, both on new built and on existing buildings. It is harmless to human health and safe to the natural environment. However, it does not determine the degree or extent of moisture intrusion. Furthermore, the smoke test is not recommended for large roofs for cost reasons. 


\subsection{Nuclear hydrogen detection (neutron backscatter) method}

Nuclear hydrogen detection (neutron backscatter) method [3] is yet another nondestructive technique for detecting roof leaks. Moisture levels are measured with a probe, yielding detailed moisture level data, showed on moisture graphs and maps of dry/ wet zones. However, this method is costly. Still it is considered viable for testing roofs larger than $200 \mathrm{~m} 2$ surface area. Therefore, it should be considered as a good option for large roofs. Although costly, this method offers a number of advantages. It is easy to use, tests can be done at any time of day or night and in any weather and even an ice covered roof is not a problem. It is also suitable for evaluating the tightness of EPDM coverings. However, processing of the data is a time-consuming process. It is also possible that smaller discontinuities will not be discovered due to the limited number of test points. Tests may be done by licensed contractors only.

\subsection{Infrared thermography}

These methods, as described in EN 13187 [5] are based on thermal imaging equipment which provides an image of the temperature distribution on a given surface (thermograms). There are two different techniques that may be used to obtain this information, chosen depending on weather conditions. The first technique consist in determination of cooling rate of the roof covering surface. After a sunny day the temperature difference between dry and wet areas will become noticeable during the following night due to a slower cooling rate of the latter. This technique can be used only during the night. The second technique, used for small sun exposure situations is based on the loss of heat from a heated building which is lower in dry locations due to a higher thermal resistance as compared to wet locations. Also this test is done at night with at least $10 \%$ difference of temperature between the building and the surrounding air.

Other conditions for thermal imaging detection include $0.7 \mathrm{~m} / \mathrm{s}$ max. wind speed and clean and dry surface of the roof. The equipment needed in the test is a thermal imaging (infrared) camera.

It is a fast and non-destructive technique for quick location of moisture intrusion areas. A desired feature is the possibility to record the measurement data and compare them between different dates and conditions. The disadvantages of this method include a relatively high cost, sensitivity to weather conditions and inconclusive results. Furthermore, it is not suitable for inverted (externally insulated) and ballast roofs. On the other hand, it is often used for testing bituminous coverings.

\subsection{Electrical methods}

Electrical methods include electrical capacitance, electrical conductance and low voltage (LV) tests. The electrical methods are completely non-destructive. 
Electrical capacitance test (ECT) [14] is based on measuring electrical capacitance between the electrodes applied on the tested material. Even a slight increase in moisture will give a considerably higher value on the capacitance meter. This method is cheap and easy in application. It can be used in different weather conditions. A weak point of this method is low repeatability of results.

Conductance test [1] is a simple yet not completely non-destructive electrical test method. It is based on measuring electrical conductance. Presently this test is rarely used for detecting roof leaks. It is because it is limited to a single point where the roof covering must be pierced to place the test electrode.

Low voltage (LV) test [1] is an excellent method for testing flat roofs covered with roofing membranes (other than EPDM). This state-of-the-art method requires installation of a system of conductors during roof covering installation. During the test water is poured on the roof surface to form a thin conductive layer to carry electrical pulses. The flow direction of the electrical charges is determined by the operator. If the meter readings indicate flow of all the electrical charges from all directions to one point, this point is the leak location. The LV test can be used on all flat roofs, other than roofs covered with EPDM membranes, and is also suitable for green, inverted and ballast roofs. It gives the exact location of leak.

\subsection{Vacuum box test}

Vacuum box test [1] is a fast and effective method for testing waterproofing membranes. This test utilises special vacuum boxes equipped with special suction cups. It is used for testing the integrity of joints in waterproofing membranes, in particular cross-joints and $\mathrm{T}$-joints. These suction cups enable testing various types of joints.

Besides the above-described tests, it may be sometimes necessary to take samples of waterproofing membranes to obtain more detailed data or to predict the durability of membranes by laboratory testing.

\section{CASE STUDY}

In order to determine the impact of environmental factors on the durability of polymeric roofing membranes a 27-year old PVC membrane reinforced with a 1.5 $\mathrm{mm}$ thick polyester mesh was compared with a brand new membrane manufactured by the same manufacturer. The examination was done using a scanning electron microscope to view features on a nanometer scale. The purpose of the analysis was to detect any discontinuities in the sample of material exposed for a period of 25 years, taken from a shaded northern part of the roof. The degree of deterioration was determined based on the results of macro and microscopic evaluation, taking into account the external impacts. The product was 
examined for: visible defects [9], geometric characteristics (length, width, straightness, flatness) [8], effective thickness and weight per unit area [11].

During the visual evaluation (unaided eye) only natural build up of dirt was detected without any significant changes in the structure, cracking, damage or alligatoring indicating a considerable loss of plasticiser (Fig. 7).

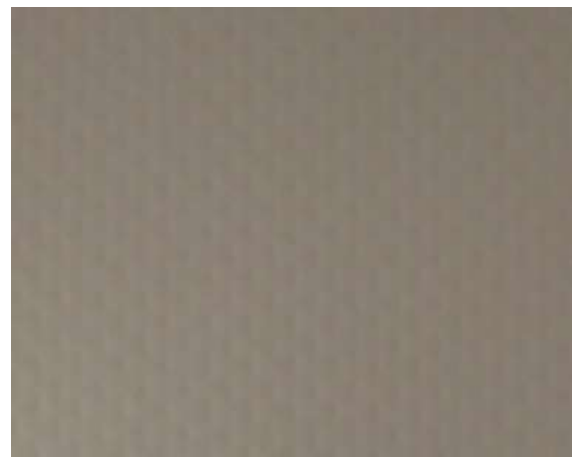

(a)

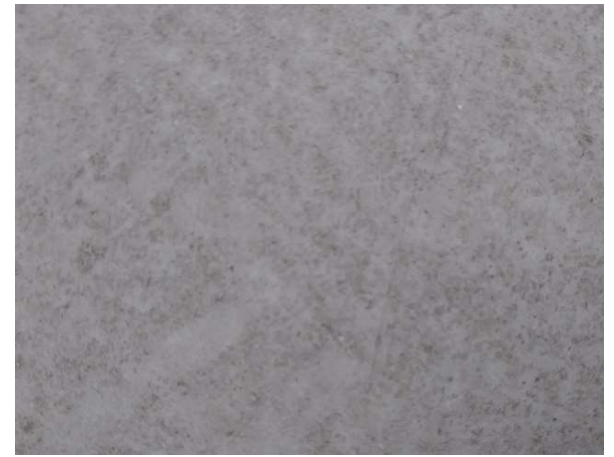

(b)

Fig. 7. Surfaces of PVC membranes: brand-new material (a) and sample of the material after 27 years in service (b) [Photo by Agata Żylińska]

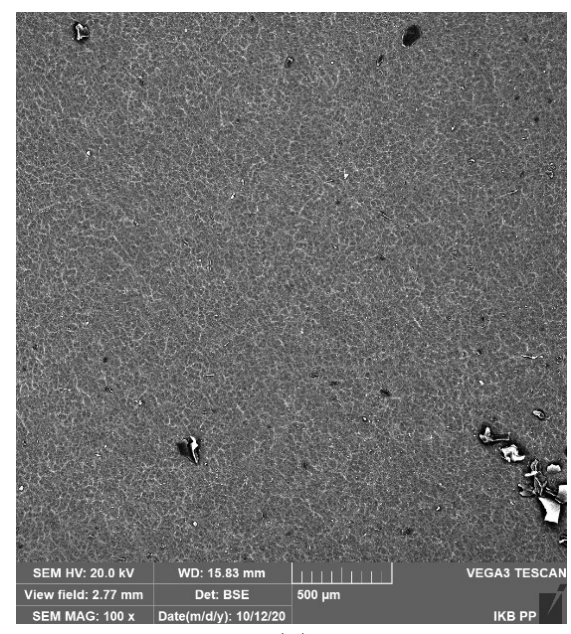

(a)

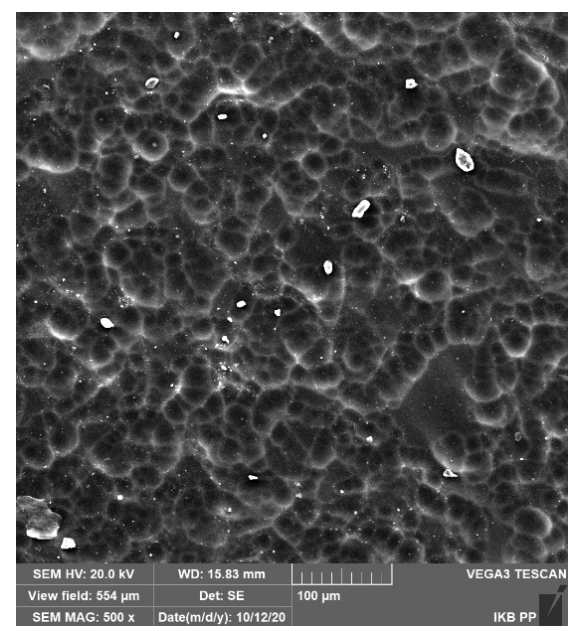

(b)

Fig. 8. SEM images of a new membrane, magnification: 100x (a) and 500x (b) [Photos by Maria Ratajczak]

The following figures compare SEM images of a new, control material (Fig. 8) and the tested piece of roofing membrane produced by the same manufacturer (Fig. 9). The SEM examination showed some degree of membrane deterioration. 
Picture No. 9 shows characteristic alligatoring, an indication of a loss of plasticiser, which is particularly evident in Picture No. 10 taken at 2.0-k magnification.

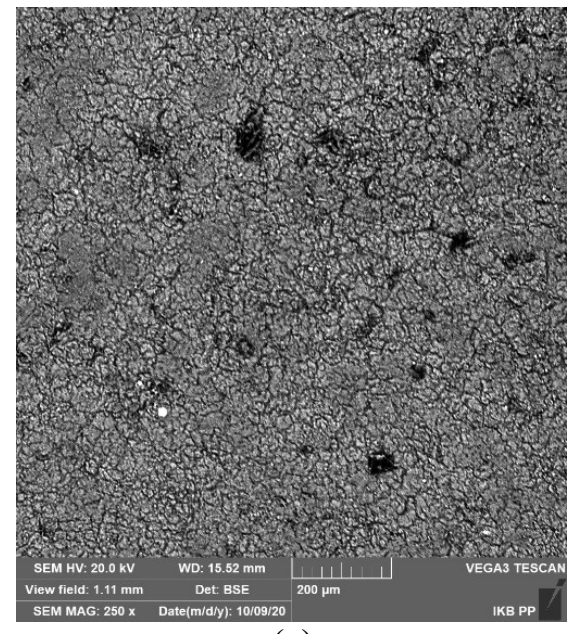

(a)

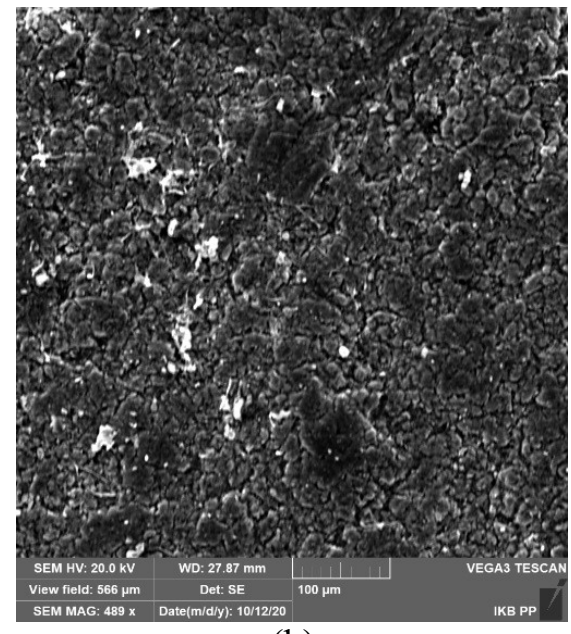

(b)

Fig. 9. SEM images of a membrane after 27 years in service, magnification: $250 x$ (a) and 500x (b) [Photos by Maria Ratajczak]

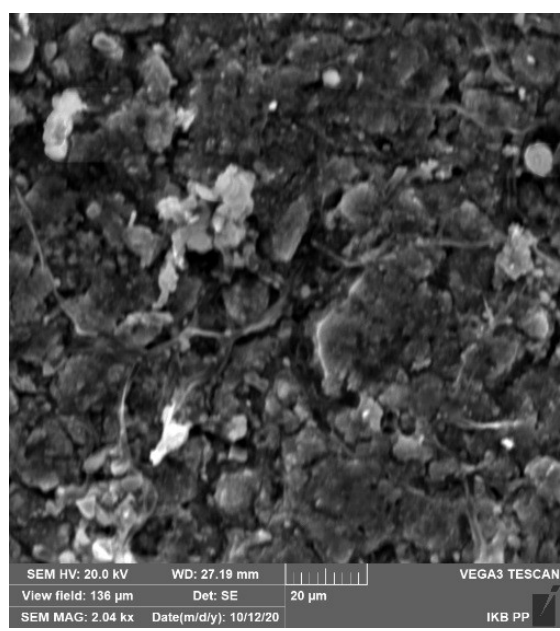

Fig. 10. SEM images of a membrane after 27 years in service, magnification: 2.0-k [Photo by Maria Ratajczak]

A control T-type joint was also checked, which is preferred over cross-joints in terms of long term integrity and strength. Before welding, the membrane pieces are bevelled to obtain a tight fitting and continuous joint. The sample passed the 
macroscopic evaluation. No delamination or discontinuities were found within the seam (Fig.11). Microscopic examination of the joint confirmed good quality of workmanship and uniform structure of the entire joint (Fig.12).

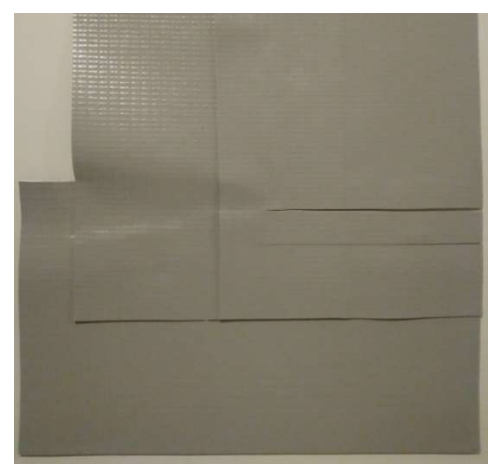

(a)

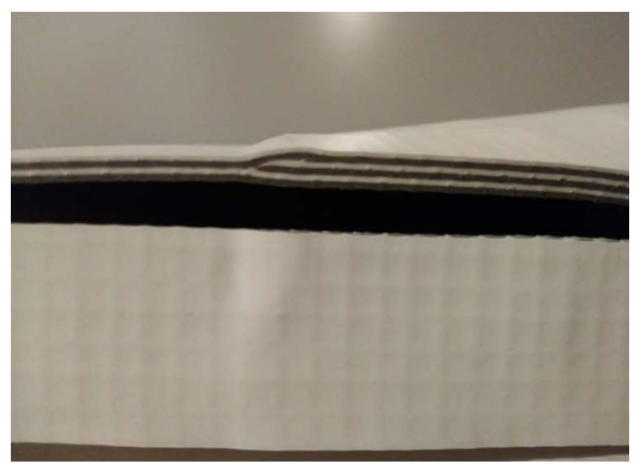

(b)

Fig. 11. Control T-type joint - view (a) and cross-section (b) [Photos by Agata Żylinska]

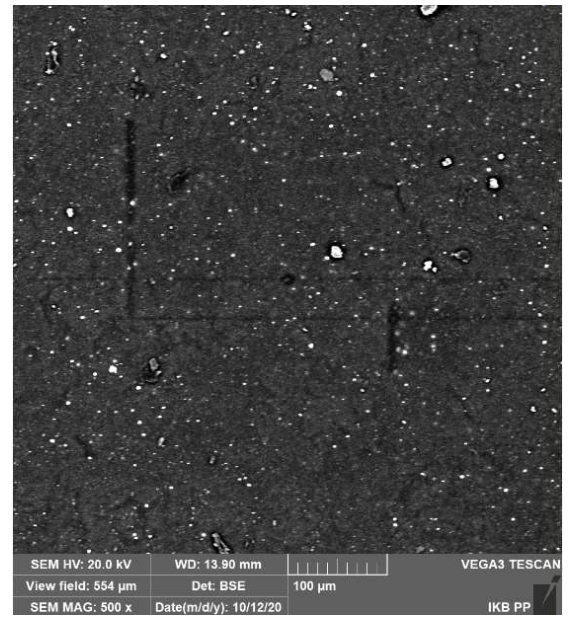

(a)

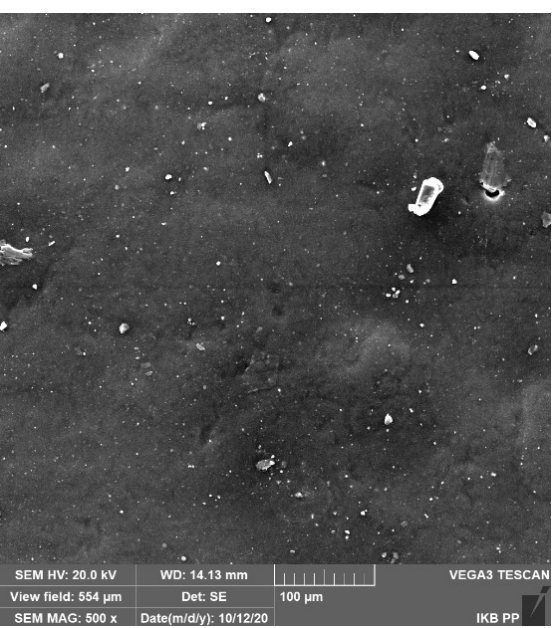

(b)

Fig. 12. SEM image of a T-type joint of a brand new roofing membrane [Photos by Maria Ratajczak]

The macroscopic examinations and SEM images showed that the material under analysis, after 27 years in service could remain in place without replacement or sealing treatment. Despite the changes on the surface, which were identified on the SEM images, the examined polymer-reinforced PVC membrane reinforced with polyester has not lost its waterproofing performance. The analysis of the 
sample taken from the northern, shaded part of the roof showed that the membrane in this area exceeded the 25 years lifetime. The unfavourable location did not affect the water tightness and did not reduce the declared service life of the material in question. This allows us to conclude that the roof orientation (translating to different environmental loads) had no bearing on the level of deterioration of the membrane. Furthermore, the sample did not exceed the declared and standard tolerances, as determined by the examination for defects and measurements of the dimensional parameters.

\section{FINAL CONCLUSIONS}

Polymeric waterproofing membranes are a material of choice for covering roofs with large surface area. There is a wide range of roofing membranes currently available on the market. Taking account of the local environmental conditions, and subject to meeting the manufacturer's requirements, including the necessary maintenance, the service life of waterproofing membranes in normal operating conditions may exceed 25 years. It is worth noting that condition assessment of the roof covering in service may turn to be problematic. Testing of this kind may be expensive or require specific systems to be included in the roofing system already at the design stage. One should bear in mind that locating of leaks on membrane coverings on large roofs is not an easy task at all. The tests and analyses carried out as part of this study showed that even with no external signs of deterioration or loss of integrity, after 15 years in service membrane coverings should undergo detailed condition surveys to assess their actual condition.

\section{REFERENCES}

1. Adamowski, J 2006. Methods and techniques for the detection of leakage of the hydroinsulation of flat roofs [in polish]. Warstwy, ściany i dachy 3, 72-73.

2. ASTM D4434 Standard Specification for Poly (Vinyl Chloride) Sheet Roofing.

3. Beer, HR, Delgado, AH, Paroli, RM and Graveline SP 2005. Durability of PVC Roofing measures - proof after long term field exposure. 10DBMC International Conference on reliability of building Materials and Components, Lyon, France.

4. DIN 16726 Plastic sheets - Testing.

5. EN 13187:2001 Thermal performance of buildings. Qualitative detection of thermal irregularities in building envelopes. Infrared method (ISO 6781:1983 modified).

6. EN 13859-1:2014-06 Flexible sheets for waterproofing. Definitions and characteristics of underlays. Part 1: Underlays for discontinuous roofing. 
7. EN 13956:2013-06 Flexible sheet for waterproofing. Plastic and rubber sheets for roof waterproofing. Definitions and characteristics.

8. EN 1848-2:2019-8 Flexible sheets for waterproofing. Determination of thickness and mass per unit area. Part 2: Plastics and rubber sheets for roof waterproofing.

9. EN 1850-2:2004 Flexible sheets for waterproofing. Determination of visible defects. Part 2: Plastic and rubber sheets for roof waterproofing.

10. EN 1991-1-1:2008 Eurocode 1: Actions on structures. Part 1-4: General actions - Wind actions.

11. EN1849-2:2019-08 Flexible sheets for waterproofing. Determination of thickness and mass per unit area. Part 2: Plastics and rubber sheets for roof waterproofing.

12. Ksit, B and Pilch, R 2019. Liquid plastic films as a solution in terms of brightness problems and problems aesthetics improvement review. Budownictwo i Architektura 18(4), 51-58.

13. Ksit, B and Szymczak-Graczyk, A 2019. Rare weather phenomenon and the work of large-format roof ratios. Civil and Environmental Engineering Reports 30(3), 123-133.

14. Kuska, Z 1974. Analysis of methods for measuring the humidity of building partitions (in polish). Prace Naukowe Instytutu Budownictwa Politechniki Wroctawskiej 12, 64-75.

15. Nowogońska, B and Korentz, J 2018. Value of consumption and costs of restoration of performance [in polish]. Materiaty Budowlane 10, 36-38.

16. Nowogońska, B. 2011 Reliability of a building thermal by the reliability of its components. Civil and Environmental Engineering Reports 6, 173-180.

17. Polymerized roof membrane durability. Institut für Bauteschutz, Baustoffe und Bauphysik Sika Services $A G$ and Sika Technology AG.

18. SIA V280 Kunststoff-Dichtungsbahnen (Polymer-Dichtungsbahnen). Anforderungswerte und Materialprüfung.

19. Szymczak-Graczyk, A 2012. Snow loads and the safety of use of building structures [in polish]. Aparatura Badawcza i dydaktyczna XVII(4), 57-62.

20. $<$ http://www.budnet.pl/Metody_i_techniki_wykrywania_nieszczelnosci,Elek tronarzedzia narzedzia budowlane, $\mathrm{i}=477 . \overline{\mathrm{h}} \mathrm{tml}>$

21. Żuranski, JA 2007. Accidents and disasters of roofs under the weight of snow in Poland [in polish]. XXIII International Conference of Structure failures, Szczecin-Międzyzdroje, Poland, May, 23-26, 357-364.

22. Żurański, JA, Gaczek, M and Fiszer, S 2009 Impact of catastrophic wind on buildings in Poland [in polish]. Przeglad Budowlany 11, 26-31.

Editor received the manuscript: 25.03 .2021 